\title{
KARAKTERISASI SENYAWA FENOL DARI KAYU BATANG MORUS NIGRA
}

\author{
Ferlinahayati $^{1 *}$, Euis Holisotan Hakim², Yana Maolana Syah ${ }^{2}$ \\ dan Lia Dewi Juliawaty ${ }^{2}$ \\ ${ }^{1}$ Jurusan Kimia Fakultas Matematika dan Ilmu Pengetahuan Alam, \\ Universitas Sriwjaya, Jalan Raya Palembang Prabumulih Km 32, Ogan \\ Ilir, Sumatera Selatan, Indonesia \\ ${ }^{2}$ Kelompok Penelitian Kimia Organik Bahan Alam Kelompok Keahlian \\ Kimia Organik, Institut Teknologi Bandung, Jalan Ganesha 10, Bandung, \\ 40132, Indonesia \\ *e-mail : etihayati74@yahoo.com
}

\begin{abstract}
ABSTRAK
Tumbuhan Morus merupakan salah satu genus utama dalam famili Moraceae. Senyawa-senyawa turunan fenol merupakan kandungan utama dari genus ini, diantaranya kelompok stilben, 2-arilbenzofuran, flavonoid dan adduct Diels Alder. Penelitian ini merupakan bagian dari penelitian mengenai kajian fitokimia terhadap tumbuhan Morus. Ekstraksi dilakukan secara maserasi terhadap kayu batang Morus nigra menggunakan pelarut metanol yang dilanjutkan dengan pemisahan menggunakan berbagai teknik kromatografi sehingga diperoleh senyawa murni. Berdasarkan data-data spektroskopi yang meliputi spektrum UV, IR dan NMR maka senyawa murni hasil isolasi tersebut merupakan senyawa fenol yaitu $\beta$-resorsilaldehid
\end{abstract}

Kata kunci: $\beta$-resorsilaldehid, Morus nigra, Moraceae

\section{CHARACTERISATION OF A PHENOLIC COMPOUND FROM THE HEARTWOOD OF MORUS NIGRA}

\begin{abstract}
Morus, is one of the major genus of Moraceae family. Phenolic compounds are the main compounds from this genus such as stilbenes, 2-arylbenzofurans, flavonoids and Diels Alder adducts. This research was a part of research on phytochemistry study of Morus plants. Extraction was conducted by maceration using methanol as a solvent, continuing by separation using a variety of chromatography techniques to found the pure isolated compound. Base on spectroscopic data including UV, IR and NMR, the phenolic isolated compound is $\beta$-resorcylaldehyde
\end{abstract}

Keywords: $\beta$-resorcylaldehyde, Morus nigra, Moraceae 


\section{PENDAHULUAN}

Morus yang lebih dikenal dengan nama "murbei" atau "bebasaran" (Jawa Barat) merupakan salah satu genus utama dari famili Moraceae selain Artocarpus dan Ficus. Tumbuhan ini terdiri dari sekitar 15 spesies dan tumbuh dengan baik di daerah beriklim sedang di wilayah Asia, Afrika dan Amerika (Venkatesh and Seema, 2008).

Di Indonesia terdapat 2 spesies Morus yaitu M. alba dan M. macroura, tapi dewasa ini beberapa spesies Morus lainnya juga ditanam di Indonesia sebagai pakan ulat sutra seperti $M$. australis, $M$. nigra, M. multicaulis dan $M$. cathayana. Selain sebagai pakan ulat sutra, buah tumbuhan ini juga dapat dikonsumsi. Secara tradisional daun muda $M$. alba digunakan untuk menambah keluarnya air susu, dan ekstrak daun digunakan untuk membersihkan darah, pengobatan bisul dan gangguan kulit (Heyne, 1987). Dalam ramuan obat tradisonal Cina, $M$. alba digunakan sebagai antiflogistik sedangkan kulit akarnya sebagai diuretik (Nomura, 1988).

Kajian fitokimia tumbuhan Morus memperlihatkan bahwa metabolit sekunder utama dari tumbuhan ini adalah senyawa turunan fenol terutama dari golongan stilben, 2-arilbenzofuran, flavonoid, adduct Diels Alder, santon dan kumarin (Nomura, et.al, 1998; Chen, et.al, 1995 dan Syah, et.al, 2000). Beberapa bioaktivitas senyawa fenolik yang telah dilaporkan dari genus ini diantaranya antinematodal, antiviral, antiplatelet, antiinflammasi, sitotoksik dan anti HIV (Syah, et. al, 2000; Hyuncheol, et.al, 2002; Du, et. al. 2003; Ko, et.al, 1997 dan Ko, et.al, 1999).

$M$. nigra merupakan salah satu tumbuhan Morus yang dibudidayakan di Indonesia. Beberapa senyawa turunan fenol yang telah dilaporkan dari tumbuhan ini antara lain adalah morunigrol $\mathrm{C}$, albafuran A dan albafuran B dari kelompok 2-arilbenzofuran (Wang, et.al; 2008), morusin dan kuwanon C dari kelompok flavonoid (Ferrari et.al, 1999), kuwanon $\mathrm{G}$ dan kuwanon $\mathrm{H}$ dari kelompok adduct Diels Alder (Ferrari et.al,1999) serta umbeliferon dan skopoletin dari kelompok kumarin (El-Tawil, et.al, 1980). Sebelumnya telah dilaporkan senyawa flavonoid dari kau batang tumbuhan M. nigra (Ferlinahayati, 2011 dan 2012). Pada penelitian ini, yang merupakan bagian dari penelitian mengenai kandungan fitokimia tumbuhan Morus Indonesia, telah berhasil diisolasi suatu senyawa fenol sederhana yaitu $\beta$ resorsilaldehid dari bagian kayu batang tumbuhan M. niga.

\section{METODE PENELITIAN}

\section{Bahan dan Alat}

Bahan tumbuhan berupa kayu batang $M$. nigra dikumpulkan dari Desa Cibeureum, Kecamatan Cisurupan, Kabupaten Garut, Jawa Barat pada bulan Juli 2005. Identitas tumbuhan ditetapkan oleh Herbarium Bogoriensis, Lembaga Ilmu Pengetahuan Indonesia (LIPI), Cibinong, Indonesia dan spesimen tumbuhan disimpan di herbarium tersebut. Bahan kimia yang digunakan adalah metanol, $n$-heksana, kloroform, etil asetat, aseton, silika gel Merck 60G, silika gel Merck 60 (70 - 230 mesh), silika gel $60 \mathrm{PF}_{254}$, sephadex LH-20 dan pelat alumunium berlapis $\mathrm{Si}$ gel Merck Kieselgel $60 \mathrm{GF}_{254}$ dengan ketebalan $0,25 \mathrm{~mm}$.

Peralatan yang digunakan berupa alat gelas yang lazim digunakan di Laboratorium Kimia Organik Bahan Alam, alat penetapan titik leleh mikro Fisher John, spektrometer Varian Cary 100 Conc, spektrometer Perkin Elmer FTIR Spectrum One dan spektrometer 
JEOL ECP400 yang bekerja pada 400 $\left({ }^{1} \mathrm{H}\right)$ and $100\left({ }^{13} \mathrm{C}\right) \mathrm{MHz}$.

\section{Prosedur Penelitian}

\section{Ekstraksi dan Isolasi}

Serbuk kayu batang $M$. nigra yang telah kering $(4,1 \mathrm{~kg})$ diekstraksi dengan cara maserasi tiga kali berturutturut (@24 jam) menggunakan pelarut metanol dan menghasilkan ekstrak metanol (153 g) setelah pelarutnya diuapkan pada tekanan rendah. Sebagian (5 x $20 \mathrm{~g}$ ) ekstrak metanol difraksinasi dengan Kromatografi Cair Vakum (KCV) menggunakan eluen $n$-heksana:EtOAc = 7:3 sampai EtOAc dan EtOAc: $\mathrm{MeOH}=$ 9:1 sehingga menghasilkan 6 fraksi utama A-F berturut-turut sebanyak 1,2; 2,1; 17,2; 7,2; 20,0; dan 7,7 g. Terhadap fraksi B (2,1 g) dilakukan fraksinasi lebih lanjut dengan menggunakan kromatografi radial menggunakan eluen $n$ heksana:EtOAc $=9: 1$ sampai $4: 6$ sehingga menghasilkan fraksi B1-B7. Selanjutnya, fraksi B3 (370 $\mathrm{mg})$ dipisahkan menggunakan kolom sephadex menggunakan eluen $\mathrm{MeOH}$ sehingga menghasilkan tiga fraksi yaitu fraksi B31-B33, dengan berat bertututturut 263, 64 dan 8 mg. Fraksi B32 (64 mg) dipisahkan lagi menggunakan kromatografi radial dengan eluen $n$ heksana: $\mathrm{CHCl}_{3}=2: 8$ sampai $1: 9$ sehingga dihasilkan senyawa hasil isolasi sebanyak $22 \mathrm{mg}$.

\section{Karakterisasi dan Penentuan Struktur Senyawa Hasil Isolasi}

Terhadap senyawa hasil isolasi dilakukan pengukuran titik leleh dan pengukuran spektroskopi yang meliputi spektroskopi UV, IR dan NMR.

\section{HASIL DAN PEMBAHASAN}

Ekstraksi yang dilakukan secara maserasi dengan menggunakan pelarut metanol terhadap kayu batang $M$. nigra dan dilanjutkan dengan pemisahan dengan KCV menghasilkan enam fraksi utama A-F. Pemisahan lebih lanjut terhadap fraksi B dengan kromatografi radial dan kromatografi kolom gravitasi (sephadex) telah menghasilkan senyawa murni sebanyak $22 \mathrm{mg}$.

Tabel 1. Data spektrum NMR senyawa hasil isolasi dan $\beta$-resorsilaldehid (Soekamto, 2003) dalam aseton- $d_{6}$

\begin{tabular}{|l|l|l|l|l|}
\hline \multirow{2}{*}{ No } & \multicolumn{2}{|l|}{$\boldsymbol{\delta}_{\mathbf{H} \text { (multiplisitas, } \boldsymbol{J} \text { dalam Hz) }} \boldsymbol{\delta}_{\mathbf{C}}$} \\
\cline { 2 - 5 } & $\begin{array}{l}\text { Senyawa hasil } \\
\text { isolasi }\end{array}$ & $\boldsymbol{\beta}$-Resorsilaldehid & $\begin{array}{l}\text { Senyawa } \\
\text { hasil isolasi }\end{array}$ & $\begin{array}{l}\boldsymbol{\beta} \text { - } \\
\text { Resorsilaldehid }\end{array}$ \\
\hline 1 & - & - & 115,8 & 115,8 \\
2 & - & - & 165,2 & 165,2 \\
3 & $6,34(d, 2,2)$ & $6,34(d d, 2,0 \& 0,6)$ & 103,1 & 103,1 \\
4 & - & - & 166,3 & 166,3 \\
5 & $6,54(d d, 2,2 \& 8,4)$ & $6,54(d d, 2,0 \& 8,5)$ & 109,6 & 109,6 \\
6 & $7,59(d, 8,4)$ & $7,59(d, 8,5)$ & 137,1 & 137,1 \\
CHO & $9,75(s)$ & $9,75(d, 0,6)$ & 195,7 & 195,7 \\
\hline
\end{tabular}




\section{Karakterisasi Senyawa Hasil Isolasi}

Senyawa hasil isolasi diperoleh berupa padatan putih kekuningan, dengan titik leleh 133-135 ${ }^{\circ} \mathrm{C}$. Pengukuran spektrum UV memberikan hasil sebagai berikut, UV (MeOH) $\lambda_{\max } \mathrm{nm}(\log \varepsilon): 212$ $(3,67), 231(3,47), 278(3,72)$ dan 312 $(3,41)$; UV (MeOH+NaOH) $\lambda_{\max } \mathrm{nm}(\mathrm{log}$ ع): $208(4,47), 250(3,37)$ dan $330(3,90)$, $\mathrm{UV}\left(\mathrm{MeOH}+\mathrm{AlCl}_{3}\right) \lambda_{\text {maks }} \mathrm{nm}(\log \varepsilon): 209$ $(3,88), 223(3,82), 302(3,98)$ dan 348 $(3,31)$ dan dengan penambahan $\mathrm{HCl}$ tidak terjadi pergeseran. Spektrum IR dalam plat $\mathrm{KBr}$ memberikan hasil sebagai berikut, $\quad v_{\text {maks }} \mathrm{cm}^{-1}: 3121(\mathrm{OH}), 1633$ $(\mathrm{C}=\mathrm{O}$ terkonjugasi), 1613, 1598, 1580, 1498 dan 1444 (C=C aromatik). Pengukuran spektrum NMR memberikan hasil sebagai berikut, ${ }^{1} \mathrm{H}$ NMR (aseton$\left.d_{6}, 400 \mathrm{MHz}\right) \delta_{\mathrm{H}}(\mathrm{ppm}): 9,75(1 \mathrm{H}, s$, CHO-7); 7,59 (1H, $d, J=8,4 \mathrm{~Hz}, \mathrm{H}-6)$; $6,54(1 \mathrm{H}, d d, J=2,2 \& 8,4 \mathrm{~Hz}, \mathrm{H}-5)$; $6,34(1 \mathrm{H}, d, J=2,2 \mathrm{~Hz}, \mathrm{H}-3)$. Spektrum ${ }^{13} \mathrm{C}$ NMR (aseton- $\left.d_{6}, 100 \mathrm{MHz}\right) \delta_{\mathrm{C}}$ (ppm): 195,7 (CHO-7); 166,3 (C-4); 165,2 (C-2); 137,1(C-6); 115,8 (C-1); 109,6 (C-5); 103,1 (C-3).

\section{Penentuan Struktur Senyawa Hasil Isolasi}

Spektrum UV senyawa hasil isolasi memberikan serapan maksimum pada $\lambda_{\max } 212,231,278$ dan $312 \mathrm{~nm}$ dalam pelarut metanol yang menunjukkan terdapatnya sistem aromatik. Terjadinya pergeseran batokromik akibat penambahan pereaksi geser $\mathrm{NaOH}$ mencirikan terdapatnya gugus hidroksil bebas pada sistem aromatik tersebut. Selain itu spektrum UV juga mengindikasikan adanya gugus hidroksil yang membentuk khelat dengan gugus karbonil yang ditunjukkan dengan terjadinya pergeseran batokromik sebesar $36 \mathrm{~nm}$ akibat penambahan pereaksi geser $\mathrm{AlCl}_{3}$ dan tidak kembali setelah penambahan $\mathrm{HCl}$. Keberadaan gugus hidroksil dan karbonil pada senyawa hasil isolasi ini didukung pula oleh spektrum IR dengan munculnya serapan untuk gugus hidroksil $\left(3121 \mathrm{~cm}^{-1}\right)$ dan karbonil terkonjugasi pada $1633 \mathrm{~cm}^{-1}$, selain itu terdapat pula serapan untuk gugus aromatik (1613-1444 $\left.\mathrm{cm}^{-1}\right)$.

Spekrum ${ }^{1} \mathrm{H}$ NMR (Tabel 1) memperlihatkan adanya satu sinyal singlet pada $\delta_{\mathrm{H}} \quad 9,75$ ppm yang merupakan sinyal untuk proton aldehid. Selanjutnya, terdapat juga tiga sinyal proton aromatik yang muncul sebagai sistem ABX pada 7,59 $(d, J=8,4 \mathrm{~Hz})$, $6,54(d d, J=2,2 \& 8,4 \mathrm{~Hz})$ dan $6,34(d$, $J=2,2 \mathrm{~Hz}$ ) yang berasal dari unit 1,2,4trisubsitusifenil. Keberadaan gugus aldehid pada senyawa hasil isolasi ini didukung pula oleh spektrum ${ }^{13} \mathrm{C}$ NMR (Tabel 1) yang diukur dengan teknik APT, dengan munculnya sinyal karbon karbonil dari aldehid pada $\delta_{\mathrm{C}} 195,7 \mathrm{ppm}$. Selain itu adanya unit 1,2,4trisubsitusifenil didukung dengan munculnya dua sinyal karbon oksiaril $\left(\delta_{\mathrm{C}}\right.$ 166,3 dan 165,2 ppm) yang menunjukkan adanya oksigenasi pada sistem aromatik dengan orientasi meta (C-2 dan C-4), tiga karbon metin dan satu karbon kuarterner. Berdasarkan data tersebut di atas dan data NMR pembanding (Soekamto, 2003) maka disimpulkan bahwa senyawa hasil isolasi memiliki struktur 2,4dihidroksibenzaldehid, yang dikenal dengan nama trivial $\beta$-resorsilaldehid dengan struktur sebagai berikut:

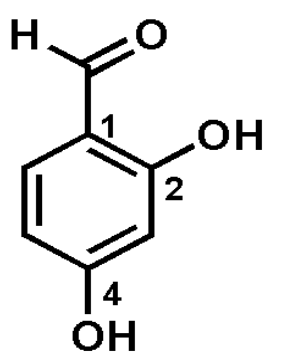

$\beta$-Resorsilaldehid 


\section{KESIMPULAN}

Pada penelitian ini telah berhasil diisolasi satu senyawa fenol dari ekstrak metanol kayu batang $M$. nigra sebanyak 22 mg. Berdasarkan data-data spektroskopi (UV, IR dan NMR) serta data senyawa pembanding maka disimpulkan bahwa senyawa fenol tersebut adalah $\beta$-resorsilaldehid.

\section{UCAPAN TERIMA KASIH}

Terima kasih disampaikan kepada Herbarium Bogoriense, PP-Biologi LIPI Cibinong yang telah mengindentifikasi spesimen tumbuhan dan kepada Dr. Jalifah Latip dari Faculty of Science and Technology, Universiti Kebangsaan Malaysia, yang telah membantu pengukuran NMR senyawa hasil isolasi.

\section{DAFTAR PUSTAKA}

Chen, F.J., N. Nakashima, I. Kimura and M. Kimura, 1995, Hypoglycemic Activity and Mechanisms of Extracts from Mulberry Leaves (Folium Mori) and Cortex Mori Radicis in Streptozotocin-Induced Diabetic Mice, Yakugaku Zasshi, 115, 476-482.

Du, J., Z.D. He, R.W. Jiang, W.C. Ye, , H.X. Xu, and P.P.H. But, 2003, Antiviral Flavonoids from the Root Bark of Morus alba L., Phytochemistry, 62(8), 12351238.

El - Tawil, B.A., M.A. Ashy, N.I. Tawfik, A.M. Khalil and S.O. Bahafi,, 1980, Constituents of Local Plants. Part 6: The Constituents of Morus nigra L. Plants, Pharmazie, 35(5-6), 324.

Ferrari, F., B. Monacelli, and I. Messana, 1999, Comparison Between in vivo and in vitro Metabolite
Paroduction of Morus nigra, Planta Medica, 65(1), 85 - 87.

Ferlinahayati, L.D. Juliawaty, Y. M. Syah, E.H. Hakim, dan J. Latip, 2011, Calkon dari Kayu Batang Morus nigra, Bull. Soc. Nat. Prod. Chem (Indonesia), 11(1), 14-18.

Ferlinahayati, E.H. Hakim, Y. M. Syah, dan L.D. Juliawaty, 2012, Senyawa Morusin dari Tumbuhan Murbei Hitam (M. nigra), Jurnal Penelitian Sains, 15(2), 70-73.

Heyne, K., 1987, Tumbuhan Berguna Indonesia II, Badan Litbang Kehutanan, Jakarta, 659-660.

Ko, H.Y., S.M. Yu, F.N. Ko, C.M. Teng and C.N. Lin, 1997, Bioactive Constituents of Morus australis and Broussonetia papyfera, $J$. Nat. Prod, 60(10), 1008 - 1011.

Ko, H.Y., J.J. Wang, H.C. Lin, J.P. Wang dan C.N. Lin, 1999, Chemistry and Biological Activities of Constituents from Morus australis, Biochemica et Biophysica Acta, 1428(2-3), 293 299.

Nomura, T., 1988, Phenolic Compounds of the Mulberry Tree and Related Plants, Progress in the Chemistry of Organic Natural Products, 53, 87-201.

Nomura, T., Y. Hano and M. Aida, 1998, Isoprenoid Substituted Flavonoids from Artocarpus Plants (Moraceae), Heterocycles, 47(2), 1179-1205.

Hyuncheol, E.K. Ko, J.Y. Jun, X.H. Oh, A.U. Park, K.H. Kang, H.S. Lee and Y.C. Kim, Planta Medica, 2002, 68(10), 932 - 934.

Soekamto, N.H., 2003, Profil Fitokimia Beberapa Spesies Moraceae Indonesia, Disertasi Program 
Doktor, Institut Teknologi Bandung.

Syah, Y.M., S.A.Achmad, E.L. Ghisalberti, E.H. Hakim, M.Z.N. Iman, L. Makmur and D. Mujahiddin, 2000, Andalasin A, A New Stilbene Dimer from Morus macroura, Fitoterapia, 71(6), 630-635.
Venkatesh, K.R. and C. Seema, 2008, Mulberry: Life Enhancer. J. Med. Plants Res, 2 (10), 271-278.

Wang, L., X.Q. Cui, T. Gong, R.Y. Yan, Y.X. Tan and R.Y. Che, 2008, Three New Compunds from the Barks of Morus nigra, J. of Asian Natural Products Research, 10(9), 897-902. 